\title{
LANDSLIDE MONITORING IN A BUILT-UP AREA
}

\author{
Petr Černoch ${ }^{a, b, *}$, JiŘí KoŠŤÁL ${ }^{b, c}$, AdAm PodoJiL ${ }^{c}$ \\ a ČEZ Energetické produkty, s.r.o. Komenského 534, 253 01, Hostivice, Czech Republic \\ ${ }^{b}$ Czech Technical University in Prague, Faculty of Civil Engineering, Department of Geotechnics, Thákurova \%, \\ 16629 Praha 6, Czech Republic \\ c INSET, s.r.o., Lucemburská 7, 130 00, Praha 3, Czech Republic \\ * corresponding author: cernoch.petr@inset.com
}

\begin{abstract}
.
The article deals with the evaluation and comparison of measured data from geotechnical monitoring of a gabion wall and an adjacent slope. In 2015, new anomalous phenomena related to deformations and a shift in the area of previously activated landslide were recorded on some monitoring elements in the area of the gabion wall. Measurements carried out in previous stages had revealed the re activation of landslides, probably due to a significant rise in groundwater levels, whose fluctuation has been up to $3 \mathrm{~m}$. A proper evaluation of the obtained results cannot be quantified without the determination of warning status or without a stability calculation. Only the trend and magnitude of the measured values can be evaluated.
\end{abstract}

KEYworDs: Monitoring, slope movements, slope stability, warning status.

\section{INTRODUCTION}

The development and expansion of cities comes up against spatial limits, making it necessary to find a way to use less suitable areas within the city which were, for many possible reasons, omitted at earlier stages of development. These are often areas with an unfavourable terrain morphology requiring expensive and time-consuming landscaping or they have a complicated geological development creating complex foundation conditions for newly emerging structures. Furthermore, these can be localities prone to geodynamic phenomena, or perhaps they are areas with shallow groundwater.

During the construction of utility lines in unfavourable geological conditions, it is essential to perform long-term and comprehensive geotechnical monitoring. Geotechnical monitoring has a basic function in any system of geotechnical risk management during construction and involving engineering and utility work, the aim of which is to monitor all the effects induced in the environment that could have an adverse influence on the construction. In localities susceptible to a loss of stability, it is necessary to monitor the speed of slope movements, changes in slope geometry and changes in the mechanical and physical properties in the landslide zone, or indeed the effectiveness of the stabilization measures used.

In this particular case, the monitoring focuses on a sloping area in the municipality of Turnov which has complex geological and hydrogeological conditions as described in the following chapter, and which impose higher demands on the construction project of a department store with an adjacent car park that is implemented. A need arose to stabilize the height difference of the store and the car park against the adjacent slope and this also involved a need to address appropriate drainage of the gabion wall.

\section{ON THE STRUCTURE CONCERNED}

\subsection{A BRIEF DESCRIPTION OF THE NATURAL CONDITIONS IN THE AREA OF THE STRUCTURE}

The slope above the store that was monitored, and stabilized by a gabion wall, is situated near the centre of the town Turnov in a commercial zone near the I/35 road. The gradient of the slope that was monitored is approximately $20^{\circ}$ towards the gabion wall. The gabion wall overcomes the height difference between the slope and the store car park (Fig. 1) and ensures the stability of the slope.

The area of interest is characterized by very complex geological conditions, which are significantly impacted by the geomorphological development of the area. During the Quaternary period, a local watercourse flowing south of the site created an erosive slope with exposed sandy marls and with considerable surface weathering. A relic of the erosive marl terrace of the stream has been preserved at the top of the slope. The southern side of the slope was subsequently flooded with a thick discordant loess drift. The following elements can be discerned from archive probes:

- The subsoil of the locality is formed by weathered sandy silt stones of the Cretaceous era, with a character of sandy-clay to clay with low plasticity and including a gradual transition to weathered and then to semi-rock marls of the R6 Class. 


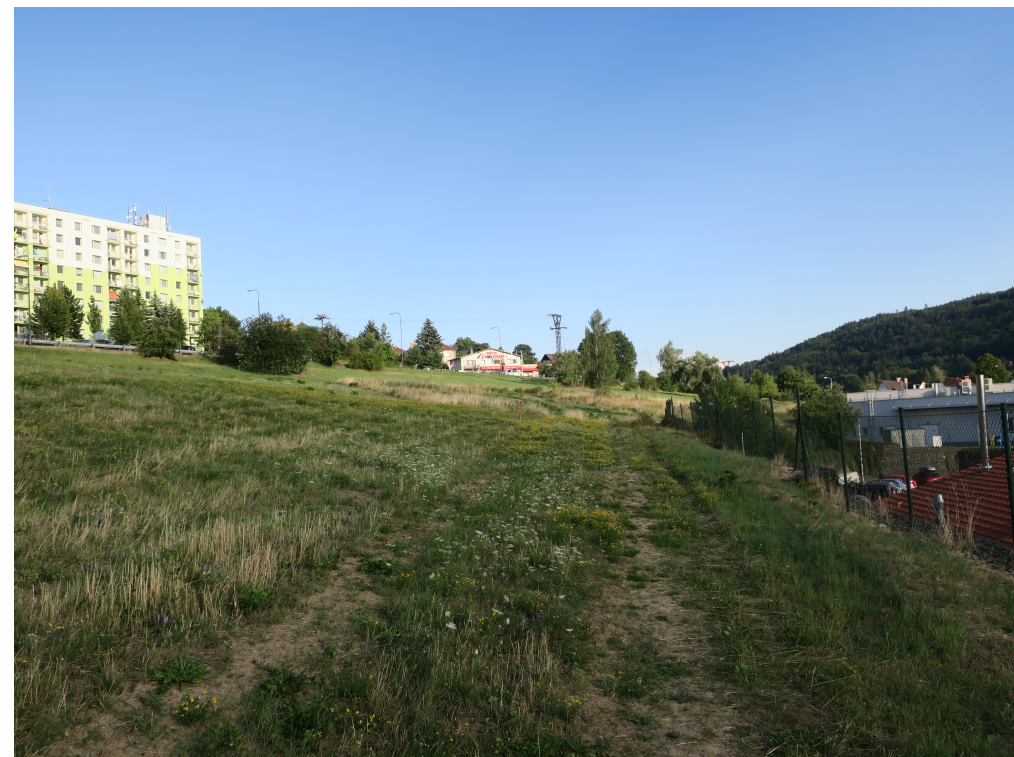

FiguRE 1. The slope above the gabion support wall, a car park with a shop (right)

- Loess drifts formed by decalcified loess clay with a soft to solid consistency of the character of sandy clay to clay with low plasticity are situated on the subsoil. In several places, gravel clay run-offs were identified.

- The upper layer of the soil horizon is composed of an upper layer of humus and a lower layer formed by sandy clays.

The hydrogeological conditions in the area of interest were conditioned by the geological structure and the articulated morphology of the terrain. The groundwater level (GWL) is about 5 to $8 \mathrm{~m}$ below the ground, with a verified fluctuation of up to $3 \mathrm{~m}$. Because of the morphology of the area, the groundwater supply would presumably be provided by atmospheric precipitation, which infiltrates by gravity through lowpermeable sandy clays (F3 MS) and locally developed moderately permeable gravel clays (F1 MG to G4 GM) to the practically impermeable subsoil formed by underlying silt stones (weathered marls on F6 CI). In periods of high precipitation, the loess clay is saturated, which leads to a change in its consistency, making it soft. The occurrence of local springs which can instigate the formation of slope movements can be expected on the slope [1].

The region concerned is characterized by low precipitation and relatively high air temperatures. The climate is warm, with a short and moderately warm spring and a short and moderately warm autumn. The winter is slightly warm, very dry and short, with a short duration of snow cover. The summer is long and warm.

\subsection{The SLOPE FAILURE MONITORING SYSTEM}

The store concerned and the adjacent car park are cut into the adjacent slope on the north side, and the gabion wall overcomes the height difference. During the construction of the gabion wall in 2005, a landslide was initiated on the slope above the car park, and which was subsequently reclaimed. Because of this extraordinary event, the monitoring system of the store under construction and the gabion wall were completed with some elements, the measurement of which was intended to verify and control the stabilization of the reclaimed landslide area (Fig. 2).

INSET Ltd. provided continuous monitoring of the gabion support wall and the adjacent slope from April 2007 to June 2018 with a measurement frequency of four times a year. Slope shifts were monitored using a system of fixed geodetic points located on the slope above the gabion wall, all measured by an accurate GPS station and a network of geodetic points located directly on the surface of the gabion wall aimed at the total station. Horizontal deformations in the depth profile of the slope were monitored by inclinometric boreholes. The groundwater level was measured and read in observation probes.

The measured values showed several years of stabilization in development trends, with oscillating movements in the range of $\pm 15 \mathrm{~mm}$. The area of the locality of interest was assessed as stabilized for many years.

\subsection{ReACTIVATION OF SLOPE MOVEMENTS}

The results of the monitoring over the years 2005-2014 indicated stable values for the movements. In 2015, slope movements were probably reactivated. On the ground, the formation of bumps - typical of slope movements - was observed at a place where there was significant water saturation [2].

Two inclinometric boreholes (located in the line of the historical landslide in a row) caught accelerating horizontal deformations documenting the formation of a sliding surface at a depth of $6 \mathrm{~m}$ below the ground (Fig. 3) with a shift along the slope line by up to 5 


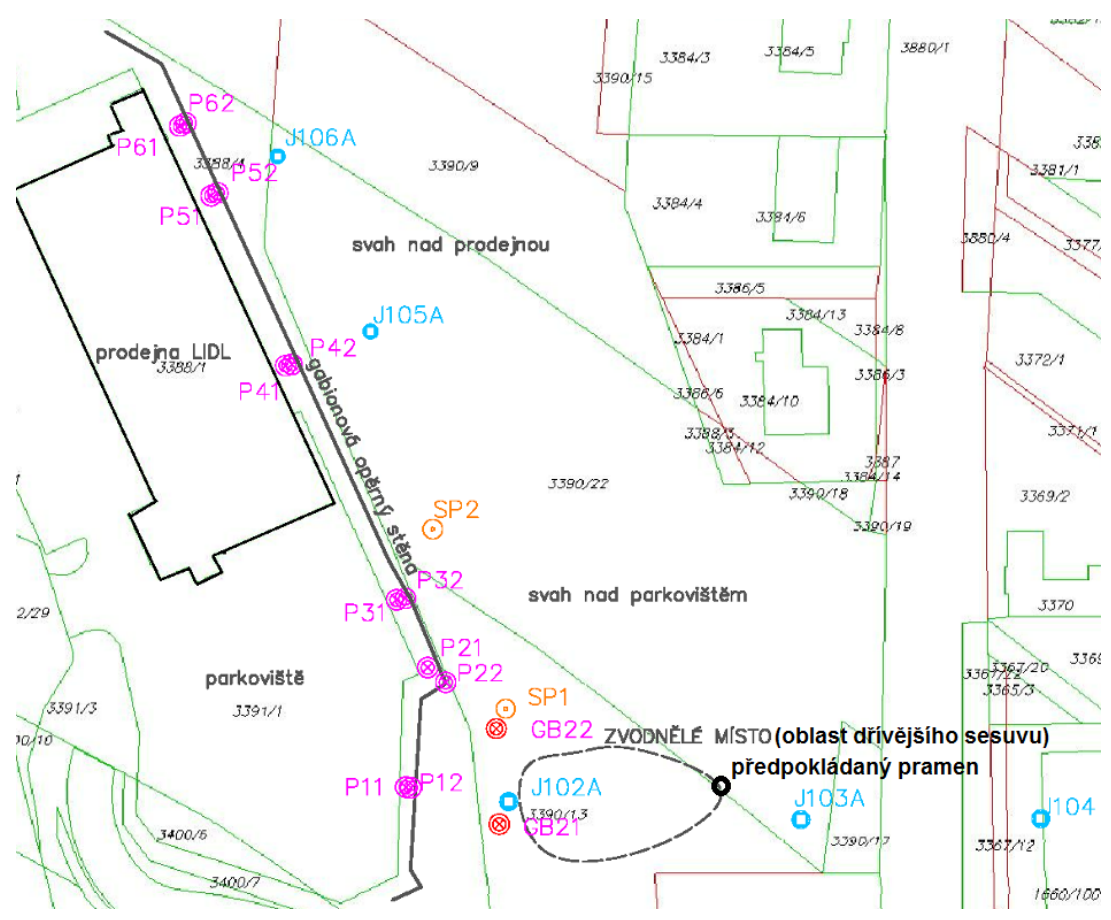

Figure 2. Monitoring system situation. P11-62: geodetic points, J102A-106A: IK boreholes, SP1 2: observation piezometers.

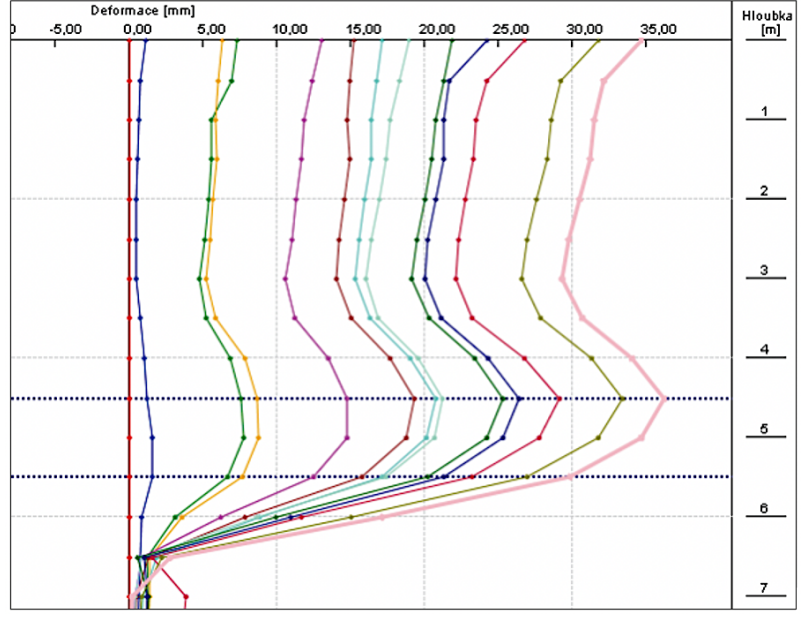

FiguRE 3. Development of inclinometric measurements over the years $2014-2018$ at the borehole J102A

mm on a quarterly basis, with an initial increase in speed. The observed deformations (shifting in the direction of the store) on the gabion wall were on the scale of millimetres.

The development of the GWL in the observation piezometers indicated the formation of a local aquifer in the area of an earlier landslide and monitored slope movements, and probably the area with developed permeable gravel sediments. The observation probes recorded a significant oscillation of the GWL by up to $3 \mathrm{~m}$, as well as significant differences in the GWL in individual probes, with a higher level in the area of the monitored landslide while probe SP1 indicated a long-term GWL at a level of about $5 \mathrm{~m}$ above sea level, compared to probe SP2, which indicated GWL at about $8 \mathrm{~m}$ below the terrain. In the area of the landslide movements a GWL supply is expected, as well as the permanently abundant spring which kept the local aquifer saturated even in periods with lower than average precipitation, the GWL in probe SP1 showing no significant correlation with precipitation.

The slope mass movements probably re-occurred as a result of an increase in the groundwater level in the area of probe SP1 (the area of the former landslide and a permanently water-saturated site) which led to increased pore pressures on the previously formed sliding surfaces. The landslide processes were linked to areas of weakened zones with a residual soil strength, which were very susceptible to changes in load conditions and hydraulic conditions 3. The movements that were detected probably did not indicate the depletion of the stability capacity in the supporting structure but functioned as a sufficient warning for the timely completion of the reclamation and stabilization measures adopted in the slope and the gabion wall.

In order to stabilize the landslide movements it was critical to reduce the GWL to below the level of the previously formed sliding surface. After the initial acceleration of the slope movements up to $1 \mathrm{~cm} /$ year, the rate of sliding has slowed to a gentler pace since 2016 (1 mm/year - the speed of the movement of the slope equal to creeping).

\subsection{Proposed solutions to Stabilization OF SLOPE MOVEMENTS}

On the basis of the monitoring of the active slope movement, which was assessed as risky as a result of the 
formation of a landslide endangering the stability of the gabion wall, the monitoring supplier recommended adopting adequate measures to lower the groundwater level. The objective of the GWL reduction was to "arrest" it below the level of the sliding surface which was identified at a depth of 6 metres below the ground in the vicinity of the borehole J102A and approx. 3 metres below the ground in the vicinity of J103A.

As part of the building conversions - a remodelling of the store and an increase in the parking capacity the investor proceeded to enhance the gabion wall with horizontal drainage boreholes to drain groundwater from the more permeable soils and to put in place a drainage groove in the area of the slope movements for effective drainage of surface water in the adjacent slope to the existing drainage system of the store and the car park [4. The conversions were further supplemented with six-strand ground anchors driven through the gabion wall, extending beyond the localized sliding surface in order to increase the stability of the gabion wall.

The aforementioned reclamation measures were implemented in 2018. The ongoing monitoring has shown a positive effect of the building conversions on the overall stability of the slope, including the gabion wall 4. Nevertheless, it is still vital to continue the monitoring.

\section{Proposed WARning Status AND MEASURES}

No opinions or recommendations for monitoring on the construction site concerned were determined by the designer, and no warning status was determined either. With no warning status determined and no stability calculation (including its verification) carried out, it was impossible to quantify the actual seriousness of the results obtained. On the basis of a professional geotechnical assessment, it was possible to evaluate the trend and size of the measured values with respect to the structural design and geometry of the supporting wall.

On the basis of the results of the long-term comprehensive monitoring and expert assessment of the development of the measured values, the following warning statuses were proposed, depending on the magnitudes of the horizontal deformations of the supporting wall and the slope at the site of the landslide movements and the development of the GWL.

\subsection{DEFINITION OF WARNING STATUS}

A) Development of the groundwater level in the locality. The swelling of the groundwater level has a negative effect on the stability of the slope masses above the sliding surface and could lead to disturbance of the stability of the gabion wall. The development of the GWL is monitored by the observation piezometers.

\begin{tabular}{ll}
\hline \multicolumn{2}{l}{ Warning status } \\
Degree & Detected condition \\
\hline $0-$ & $\begin{array}{l}\text { no shift or shifts of an oscillating nature; } \\
\text { shifts of a creep nature with a decreasing } \\
\text { gradient; }\end{array}$ \\
$2-$ & $\begin{array}{l}\text { shifts of a creep nature with a constant } \\
\text { gradient in millimetres per year; } \\
\text { shifts of a creep nature with an increas- } \\
\text { ing gradient indicating the beginning of a }\end{array}$ \\
$\quad$\begin{tabular}{l} 
landslide (cm/year). \\
\hline
\end{tabular}
\end{tabular}

B) Stability of the slope and supporting gabion wall. The stability of the slope and the gabion wall is monitored by inclinometric probes and a network of geodetic points located in the slope and on the gabion wall. The measurements are aimed at capturing changes in the speed of the slope movements and possible manifestations of displacements of the terrain, as well as deformation of the gabion wall.

\begin{tabular}{ll}
\hline \multicolumn{2}{l}{ Warning status } \\
Degree & Detected condition \\
\hline $0-$ & $\begin{array}{l}\text { no measures required; } \\
\text { compare with the development of levels }\end{array}$ \\
& $\begin{array}{l}\text { in the observation boreholes; } \\
\text { perform stability and deformation recal- } \\
\text { culation (FEM); } \\
\text { design stabilization measures. }\end{array}$ \\
\hline
\end{tabular}

\section{Discussion CONCERning THE RESULTS OF THE MONITORING}

Geotechnical monitoring is an essential safety element in the implementation and operation of structures in complex geological conditions, including geodynamic phenomena in urban built-up areas.

In this context, a landslide was monitored which exhibited reactivation on a long-term basis. However, without precisely delineated specifics and warning statuses, it is difficult to define the risk clearly and identify the necessary measures that would be acceptable and effective for the investor.

Despite the absence of warning statuses, measures stabilizing the initial landslide movements were proposed immediately after the emergency all based on the measurement results. For the time being, the following measurements show the effectiveness of the building conversions - the GWL level has been reduced and the slope movements have slowed down.

To verify the effectiveness of the reclaiming adjustments, it will be appropriate to carry out stability deformation calculations (FEM) with subsequent verification based on the data obtained from ongoing monitoring on a continuous basis. 


\section{Conclusion}

Landslide localities in built-up areas require long-term and comprehensive monitoring. The designer did not issue any opinions, recommendations, or warning statuses for the construction of the store concerned. The determination of warning statuses facilitates the evaluation of geotechnical monitoring regarding the specifics of a construction and clearly determines the measures that must be taken when declaring the appropriate level of warning status. As the emergency occurred (the landslide started again), it was necessary to propose stabilization measures and to establish warning statuses based on long-term geotechnical monitoring.

With the warning statuses introduced for the given construction, the evaluation of the measured values and the subsequent discussion with the designer and the investor on the variants of the remediation measures, all became much easier.

\section{REFERENCES}

[1] P. Černoch, J. Koštál. Geotechnical risks of foundation of warehouses built on brownfields. Ernst \& Sohn, Verlag für Architektur und technische Wissenschaften GmbH \& Co. KG, Berlin, Germany. 2018.

[2] J. Koštál. Landslide Monitoring, safety measurements, 2007 - 2018, MS. INSET s.r.o.; Prague, the Czech republic. 2018.

[3] P. Černoch, J. Koštál. Brownfields utilization and assessment of foundation construction. XVI Danube European Conference on Geotechnical Engineering; 07-09 June 2018, Skopje, R. Macedonia; Paper No. 20170407.

[4] A. Podojil. Assessment of the influence of the object Stabilization of the retaining wall on the groundwater level, MS. INSET s.r.o., Prague, the Czech republic. 2018. 